Journal of Medical Genetics 1988, 25, 289

\title{
Screening for fetal and genetic abnormality: social and ethical issues
}

On page 290 of this issue, Professor Gordon Dunstan considers the issues that arise from screening patients known to be at risk for fetal and genetic abnormality (paper presented at the King's Fund consensus meeting, December 1987, see J Med Genet 1988;25:145-6). He identifies a cluster of three "fields of choice or tension" which I hope I paraphrase correctly as (1) the reasonableness of man's desire to rectify nature's failures; (2) the sanctity of prenatal human life is not absolute; (3) the interests of the individual patient cannot be considered in isolation from their effects on others.

In considering the first of these, Dunstan is in no doubt that "God is neither jealous nor mocked" by the human wish to protect human kind from nature's failures, and he has scant regard for those who claim that medical geneticists, in doing this, 'play God'.

He observes that the prospect of severe handicap is an indication strong enough to rebut the accepted presumption in favour of life. He writes: "In hard fact, the fetus has no rights, as the law and hard reasoning understand rights, until it is born alive ... the ethics are sought in a weighing of interests, those of the unborn child and those of the mother ... . one interest . . . to be served by genetic screening . . . is an assurance that her next child should be normal".

In considering the third principle he implies that medical genetics has to take account of the social effects of an accumulation of clinical decisions made primarily in the interest of, and chosen by, individual patients. Thus, the disclosure of fetal sex in the absence of $\mathrm{X}$ linked disease, Dunstan argues, would be hard to sustain on the assumption of the parents' right to know. To facilitate abortion of a fetus because it is not the desired sex is both trivial and objectionable on the grounds, inter alia, that a multiplication of such terminations would result in an unbalanced population structure. In the case of the refusal of a patient to allow disclosure of vital information to a relative (or exceptionally an employer), issues of confidentiality may clash with social responsibility. Dunstan argues the need to obtain the patient's confidence, first in the medical geneticist and then in the programme, and then to seek willing disclosure limited to that necessary to serve individual and social interests as they emerge.

Professor Dunstan is an Anglican priest and theologian who is essentially practical, humane, resistant to absolutist views, and capable of iconoclasm if this serves to make an important point. Thus, in arguing the fundamental worth of truth he questions the need for anonymity of gamete donors and argues that registration would allow fact to be disclosed to those who need it. His paper is positive and will appeal to all. those whose chief aim is to lessen the burden of genetic disease in the community.

RODNEY HARRIS 